\title{
Sulfated Zirconia: An Efficient and Reusable Heterogeneous Catalyst in the Friedel-Crafts Acylation Reaction of 3-Methylindole
}

\author{
Darío A. Vargas ${ }^{1} \cdot$ Leticia J. Méndez ${ }^{1,2} \cdot$ Alicia S. Cánepa ${ }^{1} \cdot$ Rodolfo D. Bravo $^{1}$
}

Received: 20 January 2017 / Accepted: 17 April 2017

(C) Springer Science+Business Media New York 2017

\begin{abstract}
An efficient process for the Friedel-Crafts acylation of 3-methylindole with acid anhydrides in the presence of sulfated zirconia was developed. This catalyst shows excellent catalytic activity with good conversion and selectivity towards formation of the products of 2-acylation (3-methyl- $1 H$-indol-2-yl)ketones. Other advantages related to this process are the simple work-up procedure and smaller production of chemical waste. The catalyst was easily recycled and reused with a minimal loss in activity through three reaction cycles. The catalyst was characterized by FT-IR spectroscopy, X-Ray diffraction and superficial acidity.
\end{abstract}

\section{Graphical Abstract}

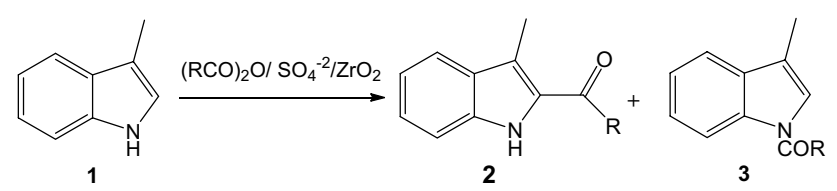

Keywords Sulfated zirconia $\cdot 3$-Methylindole $\cdot$ Ketones . Recyclability $\cdot$ Acylation reaction

Alicia S. Cánepa

ascanepa@quimica.unlp.edu.ar

1 Centro de Estudio de Compuestos Orgánicos, Departamento de Química, Facultad de Ciencias Exactas, Universidad Nacional de La Plata, Calle 47 y 115, 1900 La Plata, Argentina

2 CINDECA (CONICET-UNLP), Facultad de Ciencias Exactas, 47 No. 257, 1900 La Plata, Argentina

\section{Introduction}

Indole derivatives present wide biological importance in a variety of therapeutic areas such as anti-inflammatory, anticonvulsant, cardiovascular, antitumor, antibacterial, antiparkinsonian, antiviral and antidiabetics agents, among others [1].

In particular, acylindoles present appreciable interest, not only for their biological properties but they are also widely used as intermediates in the synthesis of alkaloid and different families of heterocyclic compounds [2, 3].

There are different methods in the synthesis of acylindoles, among them the Friedel-Crafts reactions [4-7], Vilsmeier-Haack reaction [8] and the use of Grignard reactions [9].

Some of these methods present advantages and shortcomings that limit their scope and performance. The Vilsmeier-Haack acylations also give good yields, but the amides used are limited (e.g. formamide, alkylcarboxamide) and a large amount of $\mathrm{POCl}_{3}$ is used, causing complications in the environment.

Regarding the Friedel-Crafts reaction, the electrophilic substitution preferably occurs at the C-3 instead of the $\mathrm{C}-2$ position. Acylation at the C-2 position can occur for indoles 1,3-disubstituted or 3-substituted. However, in 3-substituted indole compounds, $\mathrm{N}$-acylation may also occur [10]. The use of $N$-protecting groups is generally the chosen strategy to avoid the formation of 3-acyl derivatives [11]. The disadvantage of this process is the largest number of synthetic steps, with the initial preparation of the $\mathrm{N}$-protected derivative, subsequent acylation and removal of the protecting group to give the final product.

Our research group is interested in obtaining 2-acyl3 -methylindoles, which are used as substrates in the synthesis of complex heterocyclic compounds. Thus, 
Friedel-Crafts acylation arises as a good synthetic way of mentioned compounds from 3-methylindole, using Lewis or Brønsted acid catalysts. Homogeneous Lewis acids used for these reactions include $\mathrm{AlCl}_{3}, \mathrm{BF}_{3}, \mathrm{TiCl}_{4}$, $\mathrm{ZnCl}_{2}, \mathrm{SnCl}_{2}, \mathrm{SnCl}_{4}$ and $\mathrm{ZrCl}_{4}$ among others [7, 12-14].

These days, a number of factors demand the use of heterogeneous catalysts because of problems associated with the handling, disposal of homogeneous acids and environmental contamination.

We have studied the synthesis of different compounds through the use of homogeneous or heterogeneous acid catalysts. So, sulfuric acid, methanesulfonic acid (MSA) and trifluoroacetic acid (TFA) were used as homogeneous catalysts $[15,16]$. Moreover, many of these processes were performed using heterogeneous catalysts to compare their viability. The catalysts used were tungsten and molybdenum heteropolyacids $\left(\mathrm{H}_{3} \mathrm{PWO}_{40}\right.$ and $\mathrm{H}_{3} \mathrm{PMoO}_{40}$ ) supported on silica [17], Amberlyst 15 and Amberlyst XN-1010 resins [15, 18-21], sulfated zirconia [22, 23], $\mathrm{P}_{2} \mathrm{O}_{5}$ and $\mathrm{HClO}_{4}$ supported on silica [24]. In almost all cases, yields increased when heterogeneous catalysts were used, with simplicity in the purification process and a smaller amount of polluting waste.

Among those mentioned sulfated zirconia has attracted much attention in recent years because of its good catalytic activity, super-acidity, non-toxicity and several advantages such as short reaction times, high selectivity and the easiness of work-up procedure. Some interesting methods using this catalyst include Friedel-Crafts acylation [25], esterification reactions [26-28], synthesis of flavones [29], synthesis of coumarins by the Pechmann reaction [30] and 1,5-benzodiazepines [31].

Continuing with our work on the application of heterogeneous catalysts for development of useful synthetic methods, we decided to study the acylation of 3-methylindole using sulfated zirconia as a catalyst.

Referring to the Friedel-Crafts acylation of indole derivatives, mono- and bi-substituted products can be obtained. In relation to obtaining mono acylated products, these may be substituted at the C-2 position (2), at the $N$-position (3) and other carbon atoms in the benzene ring (4) (Scheme 1).

\section{Experimental}

\subsection{Materials}

Melting points were determined with a Buchi apparatus. ${ }^{1}$ HNMR and ${ }^{13} \mathrm{CNMR}$ spectra were recorded on a Bruker AVIII 600 Biospin in $\mathrm{CDCl}_{3}$ or DMSO- $\mathrm{d}_{6}$. Thin layer chromatography was performed on silica gel sheets $60 \mathrm{~F}_{254}$ (Merck A.G.). Silica gel 60 (70-230 mesh) (Fluka) was used for column chromatography. Commercial 3-methylindole (98\%) (Aldrich) was recrystallized from hexane before use. All reagents were purchased from Merck A.G. and Aldrich; 1,2-dichloroethane and 1,1,2-trichloroethane were distilled over phosphorous pentoxide and stored over $4 \AA$ molecular sieves. Commercial $\mathrm{SO}_{4}{ }^{-2} / \mathrm{ZrO}_{2}$ from Mel Chemical Co was dried at $110^{\circ} \mathrm{C}$ for $2 \mathrm{~h}$ in an air and was subsequently calcined for $5 \mathrm{~h}$ in air atmosphere at $550^{\circ} \mathrm{C}$, based on previous experiences [21]. All yields refer to isolated products.

\subsection{Catalyst Characterization}

The solids were characterized by FT-IR spectroscopy, $\mathrm{X}$-Ray diffraction (XRD) and superficial acidity.

$\mathrm{X}$-ray diffractograms were obtained in a Philips PW-1732 equipment, using $\mathrm{Cu} \mathrm{K} \alpha$ radiation Ni filter; $20 \mathrm{~mA}$ and $40 \mathrm{kV}$ as the high voltage source, scanning angle between $5^{\circ}$ and $50^{\circ} 2 \theta$, and scanning rate $1 \%$ min. FT-IR spectra were obtained using a Bruker IFS 66 FTIR spectrometer.

The determination of total acid sites of the catalysts was measured by potentiometric titration with $n$-butylamine in acetonitrile as a non-aqueous medium. The solid (0.05 g) was suspended in acetonitrile, and stirred for $3 \mathrm{~h}$. The suspension was titrated with a $0.05 \mathrm{~N}$ solution of $n$-butylamine in acetonitrile using a Metrohm 794 Titrino apparatus with a double junction electrode.

\subsection{Reaction Study}

Initially, the reaction between 3-methylindole (1) $(1.0 \mathrm{mmol})$ and acetic anhydride as the acylating reagent (variable amounts) was investigated as a model to optimize the experimental conditions. Sulfated zirconia was used as a heterogeneous catalyst. Parallel reactions are performed
Scheme 1 Possible products in mono acylation of 3-methylindole
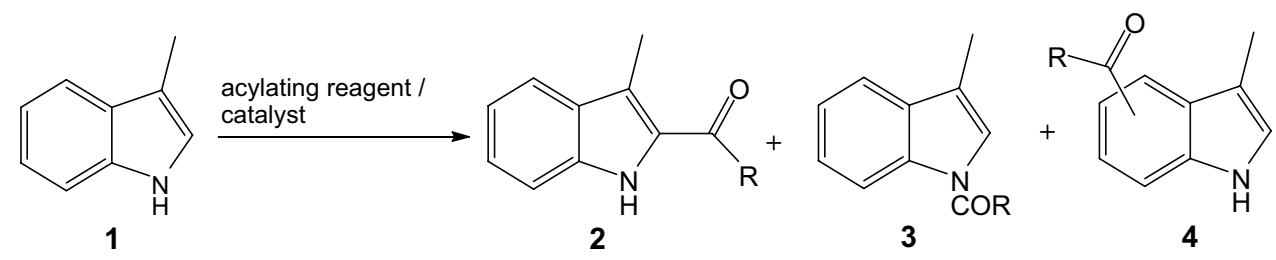
using acetic acid as an example of a homogeneous catalyst in order to compare their behavior (Scheme 1). These were carried out in a batch reactor with magnetic stirring under Ar atmosphere. The progress of the reaction was monitored by TLC (9:1 hexane/ethyl acetate). When the reaction was complete, the catalyst was separated by filtration, and the solvent was removed in vacuum. The crude products were purified by column chromatography on silica gel (9:1 hexane/ethyl acetate). The known reactions products were characterized by comparison of their physical and ${ }^{1} \mathrm{HNMR}$ and ${ }^{13} \mathrm{CNMR}$ spectra and data with those of reported ones. The identification of new compound was made through ${ }^{1}$ HNMR and ${ }^{13}$ CNMR spectra and elemental analysis.

Different reaction conditions were checked, catalyst amount, substrate/acylating reagent ratio and reaction time, for both type of catalysts.

The reactions were carried out either at $82^{\circ} \mathrm{C}$ using 1,2-dichloroethane as a solvent or at $140^{\circ} \mathrm{C}$ using 1,1,2,2-tetrachloroethane as a solvent.

\subsection{Acylating Reagent}

With the optimized conditions in hand, we probed the scope of acylation of 3-methylindole using other examples of acylating agents such as propionic anhydride, $n$-butyric anhydride and benzoic anhydride.

\subsection{Reusability of Catalyst}

The used catalysts were washed, according to the case, with 1,2-dichloroethane or 1,1,2,2-tetrachloroethane, then methanol and drying in air at $120^{\circ} \mathrm{C}$ for $2 \mathrm{~h}$ and reused in subsequent following experiments.

\section{Results and Discussion}

\subsection{Catalyst Characterization}

The properties of sulfated zirconia were examined by powder XRD, FT-IR spectroscopy and superficial acidity in catalysts calcined at $550{ }^{\circ} \mathrm{C}$, without use and after being used.

The XRD patterns of samples calcined at $550{ }^{\circ} \mathrm{C}$ without use (a) and after being used (b) are shown in Fig. 1. As can be seen from Fig. 1 sulfated zirconia calcined at $550^{\circ} \mathrm{C}$ contained only tetragonal phases $\left(2 \theta=30.16^{\circ}, 34.96^{\circ}\right.$, $50.22^{\circ}$ and $59.98^{\circ}$ ). The catalyst recovered and reused shown the same pattern of bands, without changes after three catalytic cycles.

The total number and strength of Brønsted and Lewis acids sites were measured by nonaqueous potentiometric titration with $n$-butylamine in acetonitrile. In this method,

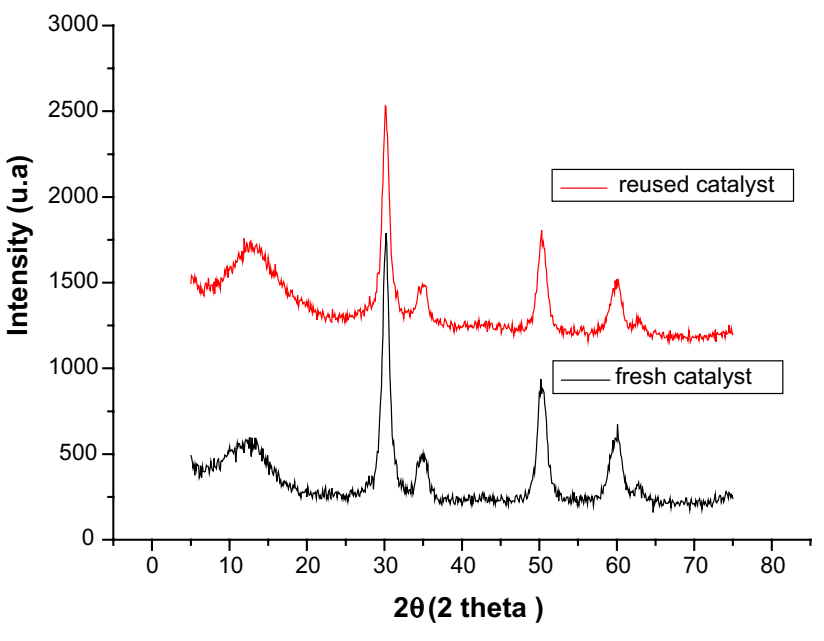

Fig. 1 XRD patterns of sulfated zirconia for fresh sample calcined at $550^{\circ} \mathrm{C}$ and a reused sample

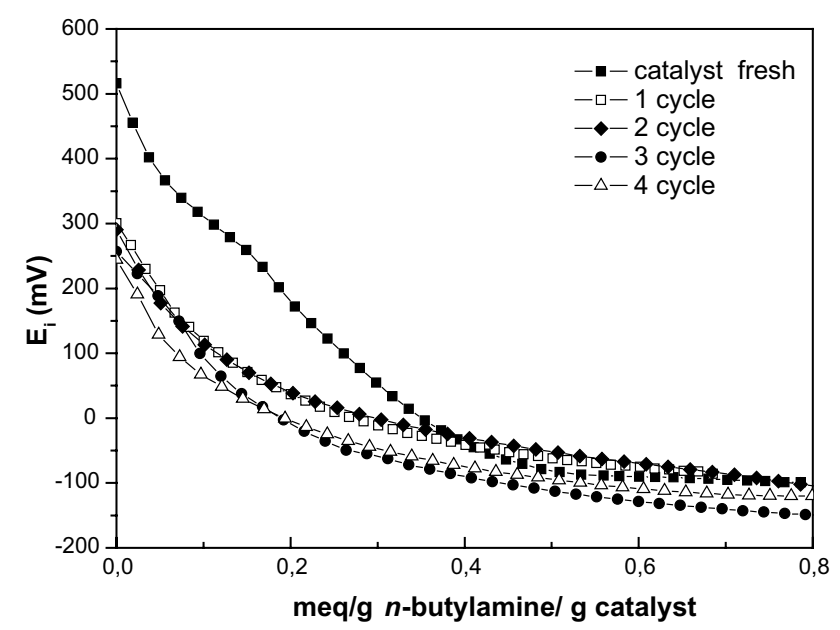

Fig. 2 Potentiometric titration of $n$-butylamine in acetonitrile for sample calcined at $550^{\circ} \mathrm{C}$ and after being used in different cycles

the initial electrode potential $\left(\mathrm{E}_{\mathrm{i}}\right)$ indicates the maximum acid strength of the surface site, and the materials with $E_{i}$ values higher than $100 \mathrm{mV}$ are defined as very strong solid acids. Additionally, the range where the plateau was reached [meq ( $n$-butylamine) $\mathrm{g}^{-1}$ ] shows the $[32,33]$.

The measurements were performed on an original sample and after being used in different cycles for the acylation reaction using acetic anhydride as acylating reagent. The potentiometric titration curves are presented in Fig. 2.

It can be observed in the Fig. 2 that the initial electrode potential $\mathrm{E}_{\mathrm{i}}$ is $516.2,303.3,290.6,257$ and $244.2 \mathrm{mV}$ for the original sample of $\mathrm{SO}_{4} / \mathrm{ZrO}_{2}$ and samples used in four catalytic cycles respectively. These results indicate the presence of very strong acid sites. 
The amount of $n$-butylamine consumed was $0.76 \mathrm{meq} / \mathrm{g}$ for the original sample of $\mathrm{SO}_{4} / \mathrm{ZrO}_{2}$ to $0.63,0.80,0.74$ and $0.75 \mathrm{meq} / \mathrm{g}$ for $\mathrm{SO}_{4} / \mathrm{ZrO}_{2}$ after four cycles respectively.

The FT-IR spectra of catalysts calcined at $550^{\circ} \mathrm{C}$, without use and after being used are shown in Fig. 3. The FT-IR spectra shown bands of the $\mathrm{SO}_{4}{ }^{-2}$ group in the region of $1200-900 \mathrm{~cm}^{-1}$, with peaks at 999, 1041, 1072, 1142 and $1235 \mathrm{~cm}^{-1}$, which are in agreement with those reported in the literature for sulfated zirconia assigned to asymmetric and symmetric stretching frequencies of ionized $\mathrm{S}=\mathrm{O}$ double bonds and $\mathrm{S}-\mathrm{O}$ bonds. An additional broad peak at $3408 \mathrm{~cm}^{-1}$ corresponds to the stretching vibrations hydroxo- and aquo-OH of hydroxyl groups and adsorbed water accompanied by the band at $1628 \mathrm{~cm}^{-1}$. In addition, the weak unresolved band between 800 and $520 \mathrm{~cm}^{-1}$ is attributed to $\mathrm{Zr}-\mathrm{O}$ stretching modes.

FT-IR spectra of reused zirconia sample washed and dried at $120^{\circ} \mathrm{C}$ showed features similar to those observed for fresh sulfated zirconia. In addition, very low intensity bands at 1456, 2850 and $2927 \mathrm{~cm}^{-1}$ can be assigned to the bending/scissoring and stretching vibration of $\mathrm{C}-\mathrm{H}$ and $\mathrm{CH}_{3}$ groups. The latter were generated, due to traces of adsorbed reagent.

\subsection{Reaction Studies}

\subsubsection{Comparison of Homogeneous and Heterogeneous Acids as Catalyst in the Acetylation of 3-Methylindole}

The key stage of this reaction mechanism involves the generation of acylium ion intermediate, obtained from the acylating reagent in the presence of a catalyst. As can be found described in literature, acylation reactions can be catalyzed by Brønsted or Lewis acid. On this occasion, acetic acid and sulfated zirconia were used as examples of

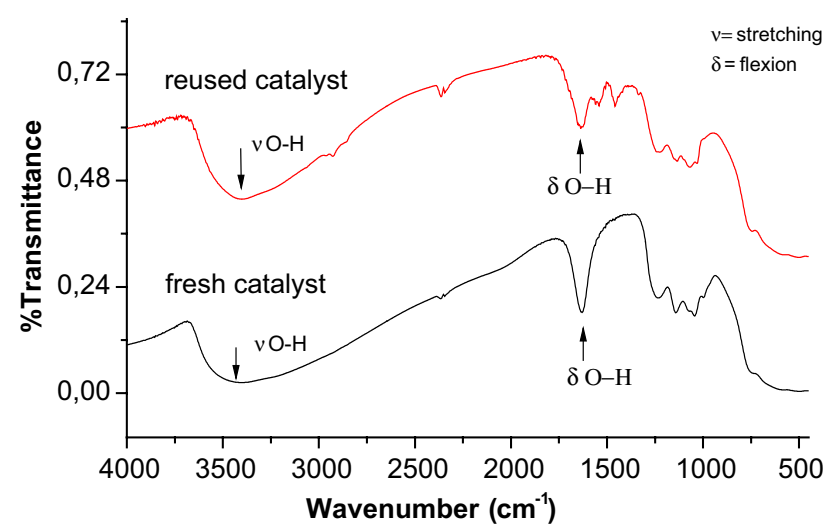

Fig. 3 FT-IR of fresh sulfated zirconia calcined at $550^{\circ} \mathrm{C}$ and reused sample homogeneous and heterogeneous catalysts. As shown in Table 1 the best results were obtained by the use of sulfated zirconia. Two products were formed, generated mainly by the substitution at C-2 position (2a) and a lower yield of $N$-acylation product (3a) (Scheme 1).

\subsubsection{Effect of Different Amounts of Sulfated Zirconia in the Acetylation of 3-Methylindole}

The effect of different amounts of sulfated zirconia was studied in the acetylation of 3-methylindole in the range $25-100 \%(w / w)$. An increase in the yield of the reaction could be observed with the increase of the proportion of catalyst employed, obtaining the best results with $100 \%$ $(\mathrm{w} / \mathrm{w})$ of sulfated zirconia (Table 1$)$.

\subsubsection{Influence of the Temperature}

To study the effect of temperature, the reaction was carried out at 82 and $140{ }^{\circ} \mathrm{C}$. The results indicate better results at $140^{\circ} \mathrm{C}$ using 1,1,2,2-tetrachloroethane as a solvent. At this temperature the products are formed in a short reaction time $(0.25 \mathrm{~h})$, greater yields and regioselectivity towards formation of product $\mathbf{2 a}$, substituted at the $\mathrm{C}-2$ position (Table 1).

\subsubsection{Influence of Molar Ratio of 3-Methylindole and Acylating reagent}

The effect of the molar ratio between 3-methylindole and acylating reagent was studied in the range 1:2-1:4. Experiments showed that a ratio of 1:4 can be considered optimal to perform this process. As could be observed in Table 1, by the use a lower ratio of acylating reagent (1:2) the yields are lower with recovery of reagent in some cases.

\subsubsection{Acylating Reagent}

The reaction of 3-methylindole (1) using other anhydrides as acylating reagents were performed in order to study the selectivity in relation to the substituent. In this regard, reactions using anhydrides with alkyl substituent $(\mathrm{R}=\mathrm{Me}$, Et and $n$-propyl) showed limited selectivity with higher yields of C-2 acylated products, relative to the $\mathrm{N}$-acylated products as shown in Table 2. In contrast, aromatic anhydride $(\mathrm{R}=\mathrm{Ph})$ provide a higher selectivity, with very good yield of C-2 acylated product (80\%), without formation of another isomer. The stabilizing effect of the phenyl group in the acylium ion generated, combined with a lower steric bulk of this group could lead to the better performance. 
Table 1 Optimization of synthesis of acetyl-3methylindole 1 using acetic anhydride as acylating reagent<smiles>COOC(C)c1[nH]c2ccccc2c1C(C)=O</smiles>

\begin{tabular}{|c|c|c|c|c|c|c|c|}
\hline Catalyst & w/w (\%) & $\begin{array}{l}\text { Ratio } \\
\text { substrate/ } \\
\left(\mathrm{CH}_{3} \mathrm{CO}\right)_{2} \mathrm{O}\end{array}$ & $\begin{array}{l}\text { Tem- } \\
\text { perature } \\
\left({ }^{0} \mathrm{C}\right)\end{array}$ & Time (h) & Yield (\%) (2a) & Yield (\%) (3a) & $\begin{array}{l}\text { Unreacted } \\
\text { reagent }(\%) \\
(\mathbf{1})\end{array}$ \\
\hline \multirow[t]{7}{*}{$\mathrm{AcOH}$} & \multirow[t]{7}{*}{100} & \multirow[t]{7}{*}{$1: 4$} & \multirow[t]{3}{*}{82} & 1 & - & - & 95 \\
\hline & & & & 3 & - & - & 93 \\
\hline & & & & 6 & - & - & 91 \\
\hline & & & \multirow[t]{4}{*}{140} & 1 & - & - & 91 \\
\hline & & & & 3 & - & - & 89 \\
\hline & & & & 6 & - & 32 & 28 \\
\hline & & & & 24 & 5 & 43 & 26 \\
\hline \multirow[t]{9}{*}{$\mathrm{ZS}$} & 25 & $1: 4$ & 82 & 1 & 40 & 28 & 27 \\
\hline & \multirow[t]{2}{*}{50} & \multirow[t]{2}{*}{$1: 4$} & 82 & 1 & 49 & 25 & 10 \\
\hline & & & 140 & 0.25 & 51 & 46 & - \\
\hline & \multirow[t]{6}{*}{100} & $1: 2$ & 82 & 1 & 46 & 35 & - \\
\hline & & $1: 4$ & & 1 & 53 & 26 & - \\
\hline & & \multirow[t]{2}{*}{$1: 2$} & \multirow[t]{2}{*}{140} & 0.25 & 51 & 25 & 10 \\
\hline & & & & 1 & 49 & 27 & 9 \\
\hline & & \multirow[t]{2}{*}{$1: 4$} & \multirow[t]{2}{*}{140} & 0.25 & 60 & 30 & - \\
\hline & & & & 1 & 61 & 30 & - \\
\hline
\end{tabular}

Table 2 Acylation of 3-methylindole $\mathbf{1}$ and acylating reagents at $140{ }^{\circ} \mathrm{C}$ using sulfated zirconia $(100 \% \mathrm{w} / \mathrm{w})$

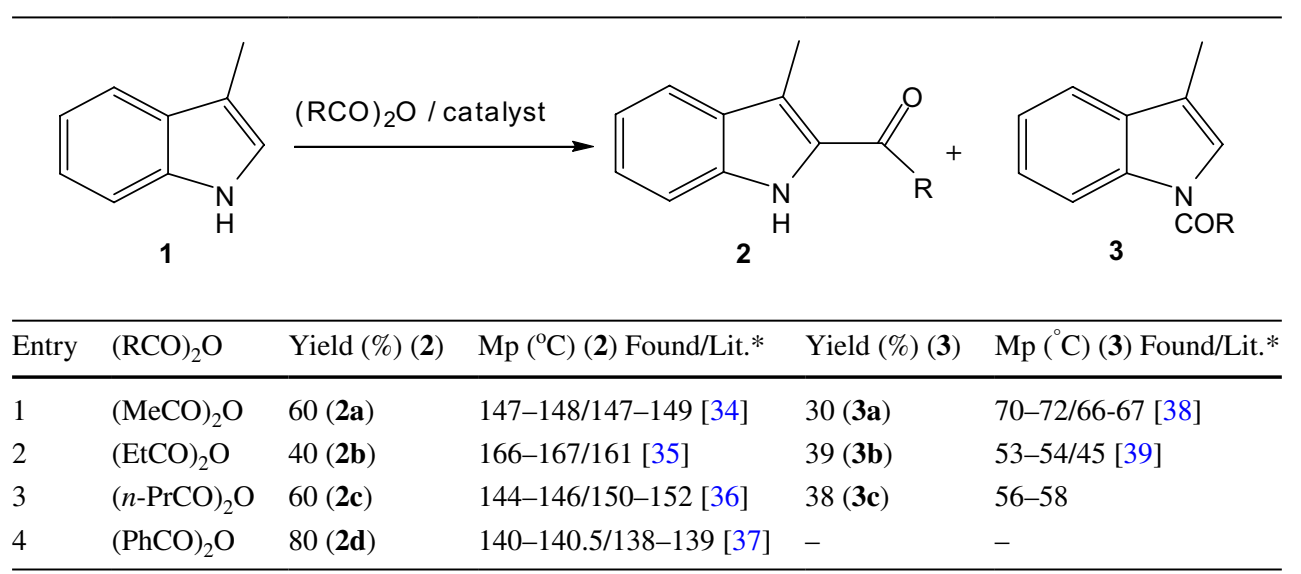

\subsection{Reusability of Catalyst}

Reusability of sulfated zirconia was also studied in the reaction to obtain 3a. The catalyst recovered after the reaction was employed in new processes. Experiments show that the sulfated zirconia can be reused without significant loss of activity until three reaction cycles (Table 3; Fig. 4).
Table 3 Catalyst reusability studied

\begin{tabular}{lll}
\hline Reaction cycle & Yield (\%) (2a) & Yield (\%) (3a) \\
\hline 1 & 60 & 30 \\
2 & 58 & 28 \\
3 & 57 & 26 \\
4 & 40 & 18 \\
\hline
\end{tabular}




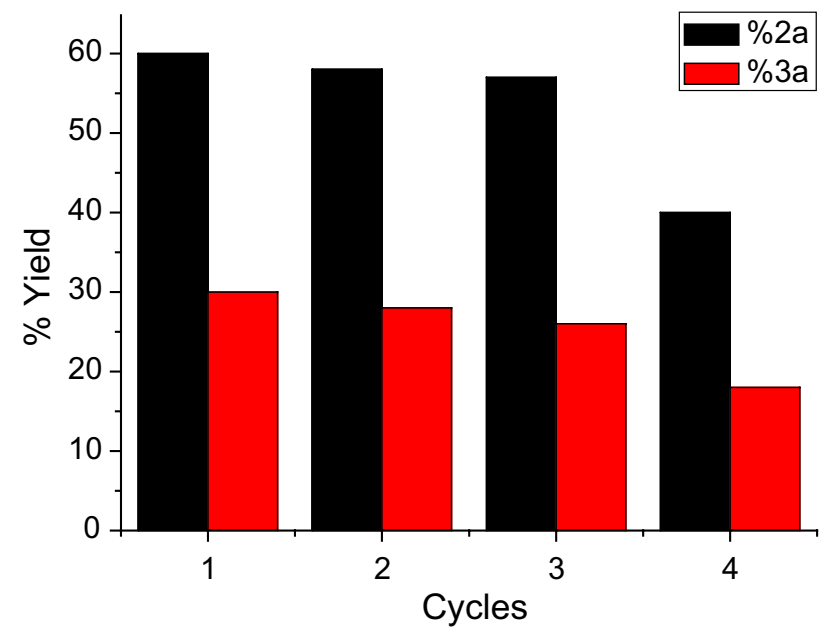

Fig. 4 Catalyst reusability

\subsubsection{Physical and Spectral Data for $\mathrm{N}$-Butyryl-3-methylindole (3c)}

Mp: $56-58{ }^{\circ} \mathrm{C} ;{ }^{1} \mathrm{H}$ NMR $\left(\mathrm{CDCl}_{3}, 500 \mathrm{MHz}\right) \delta(\mathrm{ppm}): 8.48$ (d, J = 8.2 Hz, $1 \mathrm{H}, \mathrm{H}-7$ ), 7.53 (ddd, J=7.7, 1.4, $0.7 \mathrm{~Hz}$, $1 \mathrm{H}, \mathrm{H}-4$ ), 7.38 (ddd, J = 8.4, 7.2, $1.4 \mathrm{~Hz}, 1 \mathrm{H}, \mathrm{H}-6$ ), 7.32 (td, J = 7.5, 1.1 Hz, 1 H, H-5), 7.25 (s, $1 \mathrm{H}, \mathrm{H}-2), 2.88$ (t, $\left.\mathrm{J}=7.4 \mathrm{~Hz}, 2 \mathrm{H}, \mathrm{CH}_{2} \mathrm{CO}\right), 2.32\left(\mathrm{~d}, \mathrm{~J}=1.4 \mathrm{~Hz}, 3 \mathrm{H}, \mathrm{CH}_{3}\right)$, $1.89\left(\mathrm{~h}, \mathrm{~J}=7.4 \mathrm{~Hz}, 2 \mathrm{H}, \mathrm{CH}_{3} \mathrm{CH}_{2} \mathrm{CH}_{2}\right), 1.10(\mathrm{t}, \mathrm{J}=7.4 \mathrm{~Hz}$, $\left.3 \mathrm{H}, \mathrm{CH}_{3} \mathrm{CH}_{2}\right) .{ }^{13} \mathrm{C} \mathrm{NMR}\left(\mathrm{CDCl}_{3}, 126 \mathrm{MHz}\right) \delta(\mathrm{ppm})$ : 171.11(C=O), 135.92 (C-7a), 131.32(C-3a), 125.10 (C-6), 123.26(C-5), 121.65 (C-2), 118.74(C-4), 118.15 (C-3), 116.65 (C-7), 37.77( $\left.\mathrm{CH}_{2} \mathrm{CO}\right), 18.19\left(\mathrm{CH}_{2} \mathrm{CH}_{2}\right)$, 13.83 $\left(\mathrm{CH}_{3} \mathrm{CH}_{2}\right)$, 9.72( $\left(\mathrm{CH}_{3}\right)$. Anal. Calcd for $\mathrm{C}_{13} \mathrm{H}_{15} \mathrm{NO}$ : C 77.58, H 7.51, N 6.96. Found: C 77.50, H 7.55, N 6.93.

\section{Conclusion}

In conclusion, an efficient method for the Friedel-Crafts acylation of 3-methylindole with acid anhydrides employing sulfated zirconia as catalyst has been developed. This catalyst shows an excellent catalytic activity, with good conversion and selectivity towards formation of the 2-acylation products, (3-methyl-1H-indol-2-yl) ketones. Moreover, the catalyst is air stable and easy to handle with easy work up. In addition, sulfated zirconia can be reused up to three cycles. The characterization of the catalyst performed before and after its use reveals that it did not undergo structural changes. Compared with the use of acetic acid, a better behavior and a smaller production of chemical waste were observed when sulfated zirconia was used, which gives it an additional advantage.
Acknowledgements The authors are grateful to UNLP and CICBA for financial support and Lic. Omar Guaymas for the NMR measurements. D A V and L J M are a holder of CONICET fellowship.

\section{References}

1. Sravanthi TV, Manju SL (2016) Eu J Pharm Sci 91:1-10

2. Knölker H-J (ed) (2016) The alkaloids: chemistry and biology, vol 76. Academic Press, New York 1-340

3. Sundberg RJ (ed) (1996) Indoles. Academic, London

4. Stalick WM, Wynne JH, Lloyd CT, Jensen SD, Boson S (2004) Synthesis 14:2277-2282

5. Metwally MA, Shaaban S, Abdel-Wahab BF, El-Hiti GA (2009) Curr Org Chem 13 (14): 1475-1496

6. Bai G, Li T, Yang Y, Zhang H, Lan X, Li F, Han J, Ma Z, Chen Q, Chen G (2012) Catal Commun 29:114-117

7. Guchhait SK, Kashyap M, Kamble H (2011) J Org Chem 76:4753-4758

8. Chatterjee A, Biswas KM (1973) J Org Chem 38:4002-4004

9. Bergman J, Venemalm L (1987) Tetrahedron Lett 28:3741-3744

10. Saxton JE (1952) J Chem Soc 3592-3598

11. Ketcha DM, Gribble GW (1985) J Org Chem 50:5451-5457

12. Ottoni O, de V F Neder A, Dias AKB, Cruz RPA, Aquino LB (2001). Org Lett 3(7):1005-1007

13. Pal M, Batchu VR, Parasuraman K, Yeleswarapu KR (2003) J Org Chem 68:6806-6809

14. Pal M, Dakarapu R, Padakanti S (2004) J Org Chem 69:2913-2916

15. Cánepa AS, Bravo RD (2004) J Heterocycl Chem 41:979-982

16. Cánepa AS, Bravo RD (2006) J Heterocycl Chem 43:235-238.

17. Cánepa AS, Sasiambarrena LD, Bravo RD (2008) Synth Commun 38:2655-2661

18. Cánepa AS, Bravo RD (2002) Synth Commun 32:3675-3680

19. Sasiambarrena LD, Cánepa AS, Bravo RD (2011) Synth Commun 41:200-205

20. Sasiambarrena LD, Cánepa AS, Luna CN, Bravo RD (2015) Tetrahedron Lett 56(16):2054-2058

21. Sasiambarrena LD, Cánepa AS, Bravo RD (2015) Tetrahedron Lett 56(52):7184-7189

22. Sasiambarrena LD, Méndez LJ, Ocsachoque MA, Cánepa AS, Bravo RD, González MG (2010) Catal Lett 188:180-186

23. Méndez LJ, Cánepa AS, Gónzalez MG, Bravo RD (2012) Tetrahedron Lett 53(8):688-690

24. Méndez LJ, Cánepa AS, Rimada R, Bravo RD (2013) Lett Org Chem 10 (4):240-244

25. Yadav GD, Pujari AA (1999) Green Chem 1:69-74

26. Saravanan K, Tyagi B, Shukla RS, Bajaj HC (2016) Fuel 165 298-305

27. Patel A, Brahmkhatri V, Singh N (2013) Renew Energy 51:227-233

28. Osatiashtiani A, Durndell LJ, Manayil JC, Lee AF, Wilson K (2016) Green Chem 18:5529-5535

29. Dar BD, Ahmad N, Patial J, Sharma P, Bindu K, Maity S, Singh B (2014) J Saudi Chem Soc 18:464-468

30. Yadav GD, Ajgaonkar NP, Varma A (2012) J Catal 292:99-110

31. Reddy BM, Sreekanth PM, Lakshmanan P (2005) J Mol Catal A Chem 237:93-100

32. Kuzminska M, Kovalchuk TV, Backov R, Gaigneaux EM (2014) J Catal 320:1-8

33. Altass HM, Khder AERS (2016) J Mol Catal A Chem 411:138-145.

34. Fuerstner A, Jumbam DN (1993) J Chem Soc Chem Commun 2:211-212

35. Jones CD, Suárez T (1972) J Org Chem 37(23):3622-3623 
Sulfated Zirconia: An Efficient and Reusable Heterogeneous Catalyst in the Friedel-Crafts...

36. Grinev AN, Shvedov VI, Krichevskii ES, Romanova OB, Altukhova LB, Kurilo GN, Andreeva NI, Golovina SM, Mashkovskii MD (1984) Pharm Chem J 18 (2):94-98
37. Jones CD, Suarez T (1972) J Org Chem 37:3622-3623

38. Geissman A (1952) J Am Chem Soc 74:3916-3918

39. Oddo G (1913) Gazzetta Chimica Italiana 43 (II): 198-213 